\title{
Evaluation of analytical instrumentation. Part XXIII. Instrumentation for portable X-ray fluorescence spectrometry
}

\author{
Analytical Methods Committee, Royal Society of Chemistry
}

Received: 10 January 2008/Accepted: 11 January 2008/Published online: 4 March 2008

(C) Royal Society of Chemistry 2008

\begin{abstract}
The reports of this series tabulate a number of features of analytical instruments that should be considered when making comparison between various systems. Scoring these features in a rational manner allows a scientific comparison to be made between instruments as an aid to selection. This is the XXIII report of the series and deals with instrumentation for portable X-ray fluorescence spectrometry.
\end{abstract}

Keywords Instrumentation - Overview - Evaluation .

X-ray fluorescence spectrometry

\section{Introduction}

The following report was compiled by the above SubCommittee of the AMC, which consisted of Professor S. Greenfield (Chairman), Dr. M. Barnard, Dr. C. Burgess, Mr. D. Edwards, Professor S. J. Hill, Dr. K. E. Jarvis, Dr. G. Lord, Dr. M. Sargent, Professor P. J. Potts, Dr. J. Price and Dr. M. West with Dr. E. J. Newman as Secretary. The initial input of the features for consideration was undertaken by a working party comprising Professor P. J. Potts and Dr. M. West to whom the committee expresses its thanks.

The purchase of analytical instrumentation is an important function of many laboratory managers, who may

The Analytical Methods Committee has received and approved the following report from the Instrumental Criteria Sub-Committee.

Analytical Methods Committee, Royal Society of Chemistry

The Royal Society of Chemistry, Burlington House,

Piccadilly, London W1V 0BN, UK

e-mail: vandenewman@tiscali.co.uk be called upon to choose between wide ranges of competing systems that are not always easily comparable. The objectives of the Instrumental Criteria Sub-Committee are to tabulate a number of features of analytical instruments that should be considered when making a comparison between various systems. As is explained below, it is then possible to score these features in a rational manner, which allows a scientific comparison to be made between instruments as an aid to selection.

The over-all object is to assist purchasers in obtaining the best instrument for their analytical requirements. It is hoped that this evaluation will, to some extent, also help manufacturers to supply the instrument best suited to their customers' needs. It is perhaps pertinent to note that a number of teachers have found the reports to be of use as teaching aids.

No attempt has been made to lay down a specification. In fact, the Committee considers that it would be invidious to do so: rather it has tried to encourage the purchasers to make up their own minds as to the importance of the features that are on offer by the manufacturers.

The XXIII report of the Sub-Committee deals with instrumentation for portable X-ray fluorescence spectrometry.

Notes on the use of this document.

Column 1 The features of interest.

Column 2 What the feature is and how it can be evaluated.

Column 3 The Sub-Committee has indicated the relative importance of each feature and expects users to decide on a weighting factor according to their own application.

Column 4 Here the Sub-Committee has given reasons for its opinion as to the importance of each feature. 
Column 5 It is suggested that scores are given for each feature of each instrument and that these scores are modified by a weighting factor and sub-totals obtained. The grand total will give the final score that can contribute to the selection of the instrument that best suits the user's requirements.

Notes on Scoring

1. (PS) Proportional scoring. It will be assumed, unless otherwise stated, that the scoring of features will be by proportion, e.g., Worst/0 to Best/100.

2. (WF) Weighting factor. This will depend on individual requirements. All features mentioned in the tables have some importance. If, in Sub-Committee's opinion, some features are considered to be of greater importance they are marked I. Those features of greatest importance are marked as VI (very important). A scale should be chosen for the weighting factor that allows the user to discriminate according to needs, e.g., $\mathrm{x} 1$ to $\mathrm{x} 3$ or $\mathrm{x} 1$ to $\mathrm{x} 10$.

3. (ST) Sub-total. Multiplying PS by WF obtains this.

4. In some circumstances, where there is a fundamental incompatibility between a feature of the instrument and the intended application, it may be necessary to exclude an instrument completely from further consideration.

With these requirements in mind, the user should then evaluate the instruments available on the market taking into account the following guidelines and any financial limitations. In many instances it will quickly become clear that a number of different instruments could be satisfactory and non-instrumental criteria may then become important. However, in some specialized cases only one or two instruments will have the ability or necessary features to be used in the intended application.

The guidelines are intended to be used as a checklist of features to be considered, mostly of the instrument itself, but also of service requirements and any existing relationship between the user and manufacturer. The relative importance of these features will depend on a number of factors, which in some circumstances could be subjective. However, if all the points have been considered, the choice should be informed.

The Committee consider that instrumentation for portable X-ray spectrometry is safe in normal use, but care should be taken to avoid exposure to $\mathrm{X}$-ray radiation by ensuring that all safety features are fully operational and that instrumentation is used strictly in accordance with the manufacturer's instructions.

Finally, as many laboratories are now working to established quality standards, some consideration should be given to third party certification of the manufacturer to standards such as the ISO Guide 9000 series. Such certification should extend to the service organisation.

\section{An overview of portable X-ray fluorescence spectrometry (PXRF)}

Portable X-ray fluorescence analysis offers a combination of unique advantages that cannot be rivalled by any other analytical technique:

- in situ investigation

- multi-element analytical capability

- non-destructive nature

- immediate availability to the operator of information on the chemical composition of a sample

- immediate development on a judgemental sampling strategy.

Many analytical techniques may be considered "portable" in the sense that they can be operated in a mobile laboratory that is capable of being transported to a field site to provide an immediate laboratory analytical facility. However, the particular advantage of PXRF is the capability of the technique to undertake in situ analytical measurements where the PXRF analyser is taken to, and placed in direct contact with the sample. No sample preparation is involved, the only flexibility available to the operator being sample selection. An analytical measurement is undertaken and the result is immediately available to the operator. The operator may then decide what to analyse next, giving rise to the concept of an "interactive sampling and analysis" capability that few other techniques are capable of delivering. PXRF is, therefore, normally used as a surface analytical technique. However, careful interpretation of results may be necessary in circumstances where the objective is to measure the bulk composition of a sample as the operator may need to take into account surface alteration effects such as roughness and moisture.

PXRF systems use either a miniature X-ray tube or a radioactive sealed source to excite the sample with $\mathrm{X}$-ray photons. These primary X-ray photons are capable of exciting secondary X-ray photons that are characteristic of the atoms present in the sample. The resultant X-ray spectrum is then recorded with a suitable detector such as silicon (Si-PIN) diodes, silicon drift, mercury (II) iodide $\left(\mathrm{HgI}_{2}\right)$ or a cadmium zinc telluride (CZT) device. The spectrometer usually incorporates a pre-calibration facility such that the instrument may be configured for a particular application such as:

- analysis of contaminated land

- workplace monitoring 
- particulates on filters

- analysis of surfaces, coatings and paint

- metal and alloy sorting

- architectural building or monumental stone studies

- geochemical prospecting

- archaeological investigations

- studies on works of art and archaeological artefacts

- extra-terrestrial explorations.

In theory, the technique is capable of measuring almost all the elements in the periodic table. However, as PXRF measurements are normally undertaken in air, severe attenuation of the low energy fluorescence X-rays occurs so that elements below about silicon (depending on instrument design) cannot be effectively detected. Some instruments, however, offer a partial vacuum facility to report multi-element analysis from magnesium to uranium. Elements that can be detected with highest sensitivity are those measured from the $\mathrm{K}$ line series with absorption edges just below the energy of the emissions from the excitation source. These are normally elements up to about molybdenum in the periodic table, but depend on the excitation source selected. Higher atomic elements can normally be determined, but at a lower sensitivity as the L-series lines must be used for detection.

The mass of sample analysed depends on the energy of the characteristic fluorescent X-ray and its associated critical penetration depth within the sample. Critical penetration depths for the lower atomic number elements are in the $\mu \mathrm{m}$ range, and if higher atomic elements determined from the $\mathrm{K}$-line, 1-2 $\mathrm{mm}$ (for Mo $\mathrm{K}$ in soil) or more is the relevant figure. The best estimate of analysed mass is, therefore, in the mg to $g$ range.

Modern instruments are extremely compact and light in weight as illustrated below.

The apotheosis of such instrumentation are systems designed for extra-terrestrial measurements, such as the Beagle 2 PXRF, of mass $280 \mathrm{~g}$, designed for measurements of rock and soil on the surface of Mars.

All instruments are designed and built to satisfy statutory, international X-ray safety legislation with appropriate interlocks and adequate radiation shielding. In addition, instruments fitted with radioactive sealed source(s) must comply with regulations covering the transportation of such devices (Table 1).
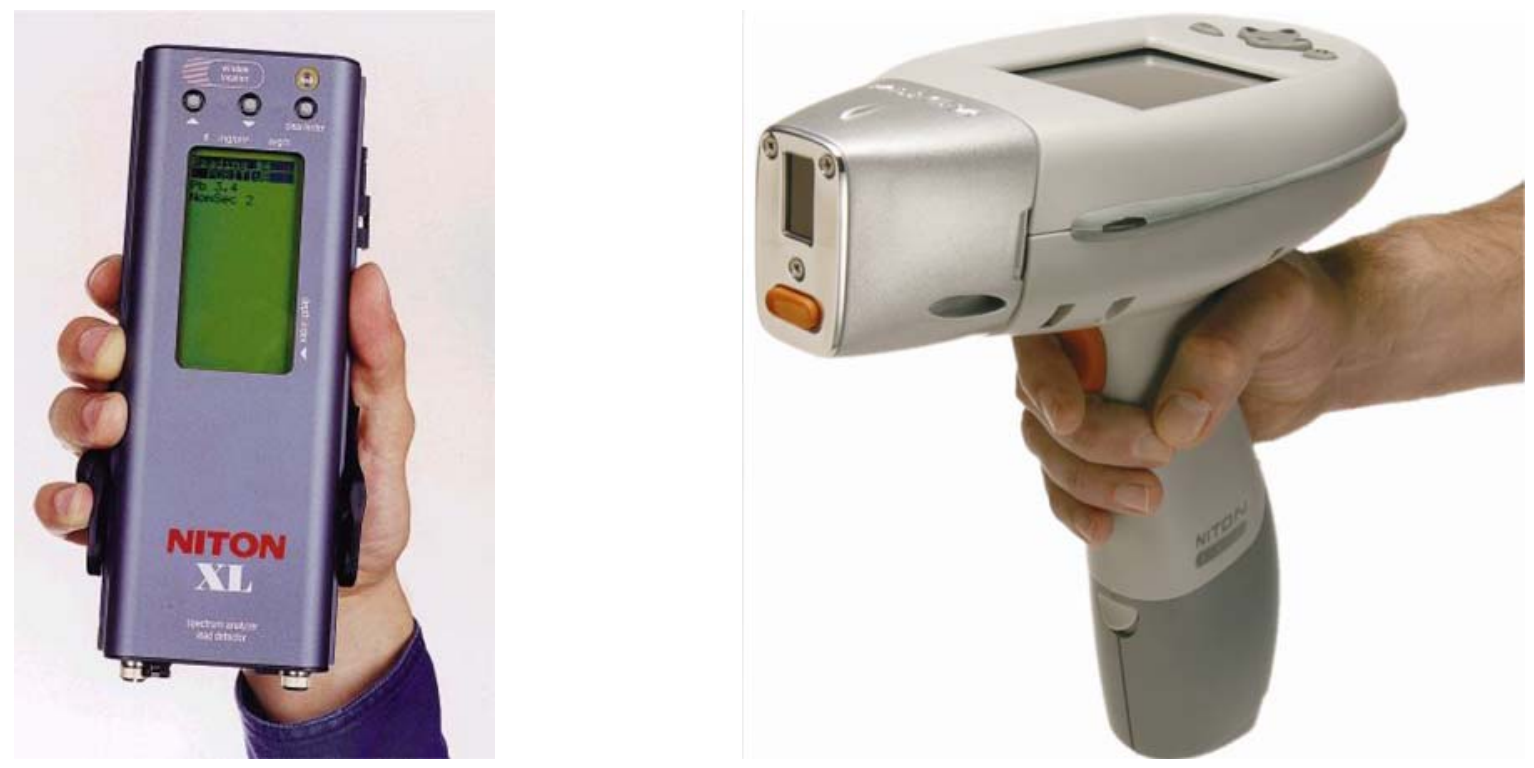
Table 1 Instrumental criteria sub-committee evaluation form

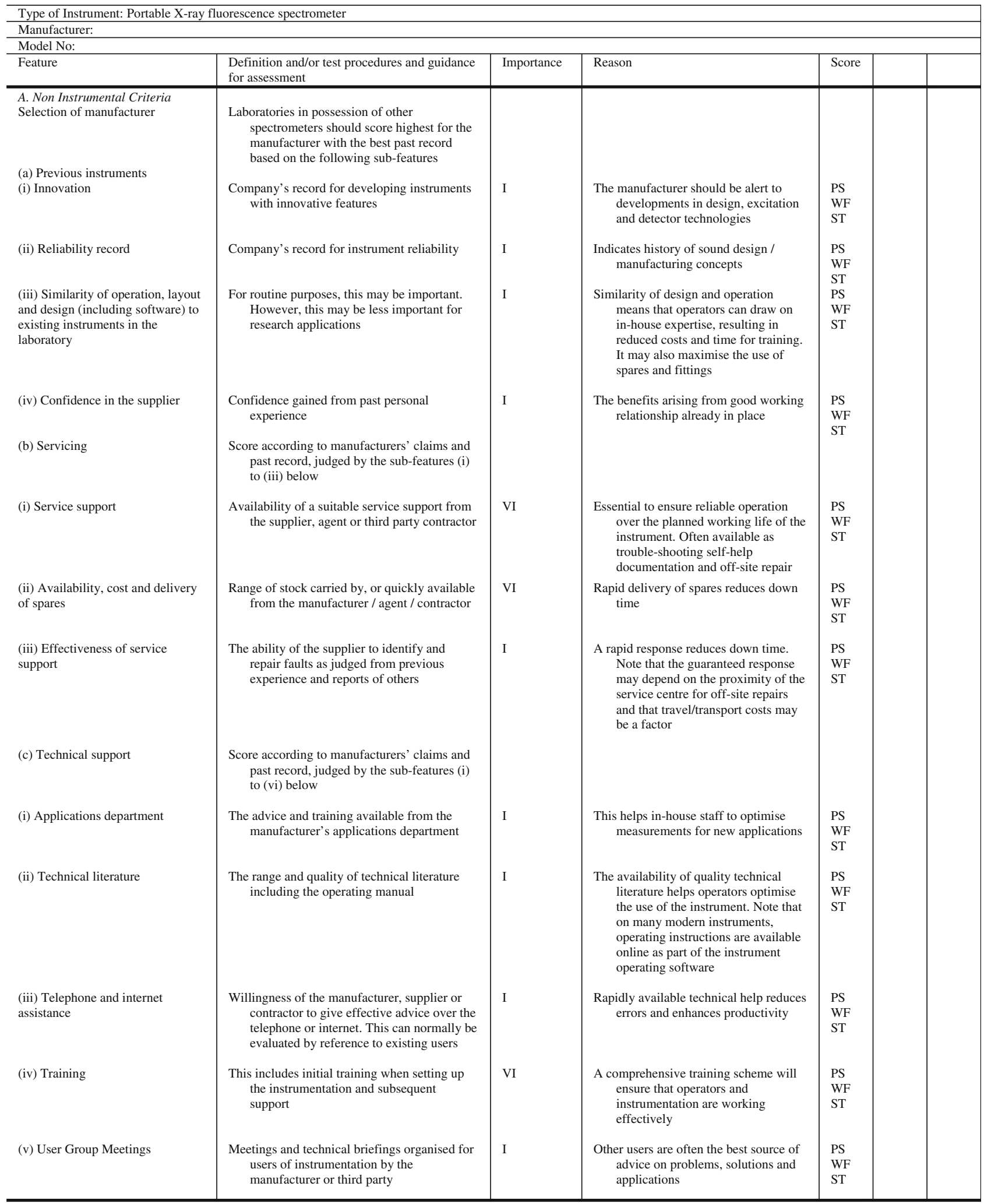


Table 1 continued

\begin{tabular}{|c|c|c|c|c|}
\hline Feature & $\begin{array}{l}\text { Definition and/or test procedures and guidance } \\
\text { for assessment }\end{array}$ & Importance & Reason & Score \\
\hline (vi) Risk assessment & $\begin{array}{l}\text { Score according to the support available from } \\
\text { manufacturers in the development of } \\
\text { appropriate risk assessments }\end{array}$ & I & $\begin{array}{l}\text { Because of the mode of operation } \\
\text { and the intimate interaction } \\
\text { between instrument } \\
\text { and operator, special consideration } \\
\text { is required for the development of } \\
\text { risk assessment to comply with } \\
\text { legislation designed to minimise the } \\
\text { risk of accidental exposure to } \\
\text { ionising radiation }\end{array}$ & $\begin{array}{l}\text { PS } \\
\text { WF } \\
\text { ST }\end{array}$ \\
\hline B. Instrumental Criteria & $\begin{array}{l}\text { The specific tests recommended in this report } \\
\text { should be discussed with the instrument } \\
\text { manufacturer in advance of any evaluation } \\
\text { to ensure that any testing is undertaken in a } \\
\text { practical and effective manner, taking } \\
\text { account of effective health and safety } \\
\text { procedures especially with respect to } \\
\text { ionising radiation }\end{array}$ & & & \\
\hline $\begin{array}{l}\text { 1. General Features Facilities } \\
\text { required for: } \\
\text { (a) Size and portability of } \\
\text { equipment }\end{array}$ & $\begin{array}{l}\text { Score according to weight and practical } \\
\text { portability for envisaged use off-site }\end{array}$ & $\mathrm{I} / \mathrm{VI}$ & $\begin{array}{l}\text { The instrument and any accessories may } \\
\text { need to be carried and used in hand } \\
\text { held mode at field sites for extended } \\
\text { periods of time. The comfort and } \\
\text { effective use by the operator will be } \\
\text { influenced by the weight of the } \\
\text { instrument and various } \\
\text { ergonometric design features that } \\
\text { promote hand held operation }\end{array}$ & $\begin{array}{l}\text { PS } \\
\text { WF } \\
\text { ST }\end{array}$ \\
\hline (b) Suitability for field use & $\begin{array}{l}\text { Score according to design features that ensure } \\
\text { effective field use, including ruggedness } \\
\text { (as evidenced by drop test data), water } \\
\text { proofing and dust proofing, and effective } \\
\text { operation at the range of temperatures that } \\
\text { will be encountered at a field site, taking } \\
\text { account of the envisaged use }\end{array}$ & I /VI & $\begin{array}{l}\text { PXRF instrumentation may be used in } \\
\text { some demanding environments } \\
\text { including outdoors (including in } \\
\text { wet weather) and at various types of } \\
\text { industrial sites. Features will then } \\
\text { need to be designed into } \\
\text { instrumentation to ensure the } \\
\text { effective and enduring operation of } \\
\text { the instrumentation }\end{array}$ & $\begin{array}{l}\text { PS } \\
\text { WF } \\
\text { ST }\end{array}$ \\
\hline $\begin{array}{l}\text { (c) Shape and size of analytical } \\
\text { window and contact surface }\end{array}$ & $\begin{array}{l}\text { Score according to the shape and size of the } \\
\text { analysis window and analytical plane of } \\
\text { the instrument which is placed in contact } \\
\text { with the sample surface to be analysed }\end{array}$ & I & $\begin{array}{l}\text { Instruments that are to be used to } \\
\text { analyse surfaces where there is } \\
\text { restricted access (for example } \\
\text { welds) will benefit from a narrow } \\
\text { 'snout' to facilitate contact when } \\
\text { there is restricted access. } \\
\text { Instruments for use in analysing } \\
\text { large flat surfaces will benefit from } \\
\text { a larger window and flat surface } \\
\text { that can easily be registered in } \\
\text { contact with the sample surface. An } \\
\text { appropriate compromise will need } \\
\text { to be made for general purpose } \\
\text { instruments }\end{array}$ & $\begin{array}{l}\text { PS } \\
\text { WF } \\
\text { ST }\end{array}$ \\
\hline $\begin{array}{l}\text { (d) Self supporting field and } \\
\text { laboratory operation }\end{array}$ & $\begin{array}{l}\text { Score for features that allow the instrument to } \\
\text { be operated in the field in a self supported } \\
\text { mode and accessories that allow the } \\
\text { instrument to analyse samples safely and } \\
\text { effectively in the laboratory if these modes } \\
\text { of operation are important to the intended } \\
\text { application }\end{array}$ & & $\begin{array}{l}\text { In some applications, for example in the } \\
\text { analysis of soil, it is convenient to } \\
\text { place the instrument on the sample } \\
\text { and operate it remotely, rather than } \\
\text { the operator needing to hold the } \\
\text { instrument with the analysis trigger } \\
\text { being permanently depressed for } \\
\text { the duration of the analysis. In this } \\
\text { mode of operation, the instrument } \\
\text { must be designed to be self } \\
\text { supporting (some instruments will } \\
\text { fall over!). For the most versatile } \\
\text { use, it is often convenient to be able } \\
\text { to analyse samples in the laboratory } \\
\text { with the instrument supported in an } \\
\text { appropriate stand and the analysis } \\
\text { window enclosed in a suitable lid or } \\
\text { enclosure. In both modes of } \\
\text { operation, consideration will need } \\
\text { to be made for the appropriate use } \\
\text { of radiation interlocks. Scoring is } \\
\text { important if these modes of } \\
\text { operation are important in the } \\
\text { intended application }\end{array}$ & \\
\hline
\end{tabular}


Table 1 continued

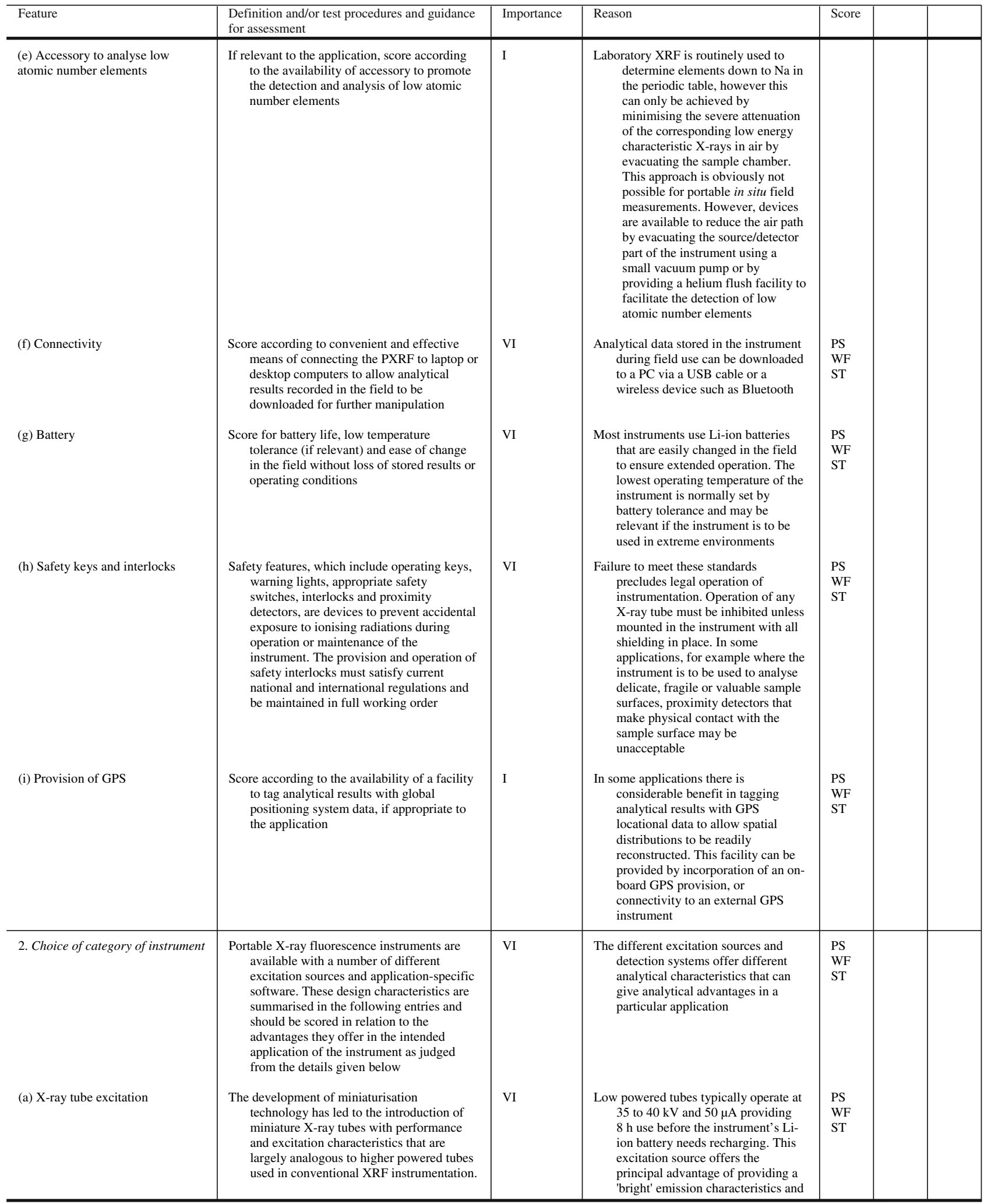


Table 1 continued

\begin{tabular}{|c|c|c|c|c|}
\hline Feature & $\begin{array}{l}\text { Definition and/or test procedures and guidance } \\
\text { for assessment }\end{array}$ & Importance & Reason & Score \\
\hline (b) Radioisotope excitation & $\begin{array}{l}\text { The sample is excited using an appropriate } \\
\text { sealed radioactive source such as }{ }^{55} \mathrm{Fe} \text {, } \\
{ }^{244} \mathrm{Cm},{ }^{109} \mathrm{Cd} \text { and } / \mathrm{or}^{241} \mathrm{Am} .\end{array}$ & VI & $\begin{array}{l}\text { does not require a licence under } \\
\text { radioactive substances legislation } \\
\text { for sealed sources thus avoiding } \\
\text { restrictions on transport and use } \\
\text { across national boundaries. } \\
\text { Radioactive source excitation is an } \\
\text { effective way of meeting criteria for } \\
\text { minimising the power consumption } \\
\text { of PXRF instrumentation and } \\
\text { facilitates the development of } \\
\text { compact instrumentation optimised } \\
\text { for a specific application. More } \\
\text { than one source (with the } \\
\text { complication of an exchange } \\
\text { mechanism) may be required for } \\
\text { multi-element applications. } \\
\text { Effective shielding must be } \\
\text { provided even when the instrument } \\
\text { is not in use and ownership of the } \\
\text { instrument requires a licence under } \\
\text { radioactive substances legislation } \\
\text { that places restrictions on the use, } \\
\text { storage, custody and transport of } \\
\text { the instrument within national } \\
\text { boundaries. }\end{array}$ & $\begin{array}{l}\text { PS } \\
\text { WF } \\
\text { ST }\end{array}$ \\
\hline $\begin{array}{l}\text { Particular features relevant } \\
\text { to each of these categories } \\
\text { of instrumentation will now } \\
\text { be considered as follows: } \\
\text { 3. X-ray tube excitation } \\
\text { (a) X-ray tube }\end{array}$ & $\begin{array}{l}\text { Miniature low-power X-ray tubes provide a } \\
\text { potential flexible excitation source. Score } \\
\text { according to the availability of a tube with } \\
\text { an anode appropriate for the intended } \\
\text { application } \\
\text { Score according to the ease of the tube } \\
\text { exchange procedure. Safety considerations } \\
\text { may restrict this activity to trained service } \\
\text { personnel, in which case, speed, } \\
\text { convenience and cost will be the features } \\
\text { to be scored }\end{array}$ & I & $\begin{array}{l}\text { An X-ray source provides a bright } \\
\text { source of excitation. Since the } \\
\text { range of elements that can be } \\
\text { excited with optimum sensitivity is } \\
\text { largely dictated by the tube anode it } \\
\text { is important that the appropriate } \\
\text { anode is available. (Au offers } \\
\text { improved sensitivity for toxic } \\
\text { elements such as Cd, whereas a Ag } \\
\text { anode may be preferred for } \\
\text { "lighter" analytes) } \\
\text { Occasional replacement may be } \\
\text { necessary following tube failure. It } \\
\text { is important that these operations } \\
\text { can be undertaken simply. } \\
\text { Changing tubes should only be } \\
\text { undertaken by a fully qualified } \\
\text { operator }\end{array}$ & $\begin{array}{l}\text { PS } \\
\text { WF } \\
\text { ST }\end{array}$ \\
\hline (c) Power settings & 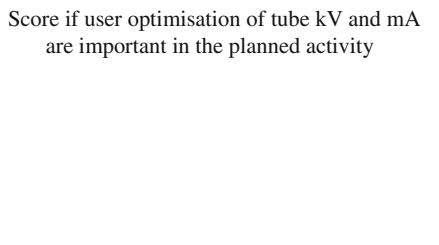 & I & $\begin{array}{l}\text { In simple applications, the } \mathrm{X} \text {-ray tube } \\
\text { may be operated under fixed } \\
\text { conditions of applied } \mathrm{kV} \text { and } \mathrm{mA} \\
\text { and scoring may then be } \\
\text { inappropriate. However, } \mathrm{X} \text {-ray } \\
\text { tubes can be optimised for the } \\
\text { excitation of different ranges of } \\
\text { elements by adjusting the tube } \mathrm{kV} \\
\text { (and } \mathrm{mA} \text { ) }\end{array}$ & $\begin{array}{l}\text { PS } \\
\text { WF } \\
\text { ST }\end{array}$ \\
\hline (d) Primary beam filters & $\begin{array}{l}\text { Score if optimisation of excitation conditions } \\
\text { by use of a primary beam filter is } \\
\text { important in the intended application. In } \\
\text { the most demanding applications, primary } \\
\text { beam filters may offer advantage }\end{array}$ & I & $\begin{array}{l}\text { Primary beam filters are thin metallic } \\
\text { (or polymer) foils placed between } \\
\text { tube and sample to modify the } \\
\text { spectrum available to excite the } \\
\text { sample. Filters can be used to } \\
\text { improve detection limits by } \\
\text { removing a proportion of the tube } \\
\text { continuum that would otherwise be } \\
\text { scatteredoff the sample into the } \\
\text { detector, degrading the signal to } \\
\text { background ratio of elements of } \\
\text { interest }\end{array}$ & $\begin{array}{l}\text { PS } \\
\text { WF } \\
\text { ST }\end{array}$ \\
\hline
\end{tabular}


Table 1 continued

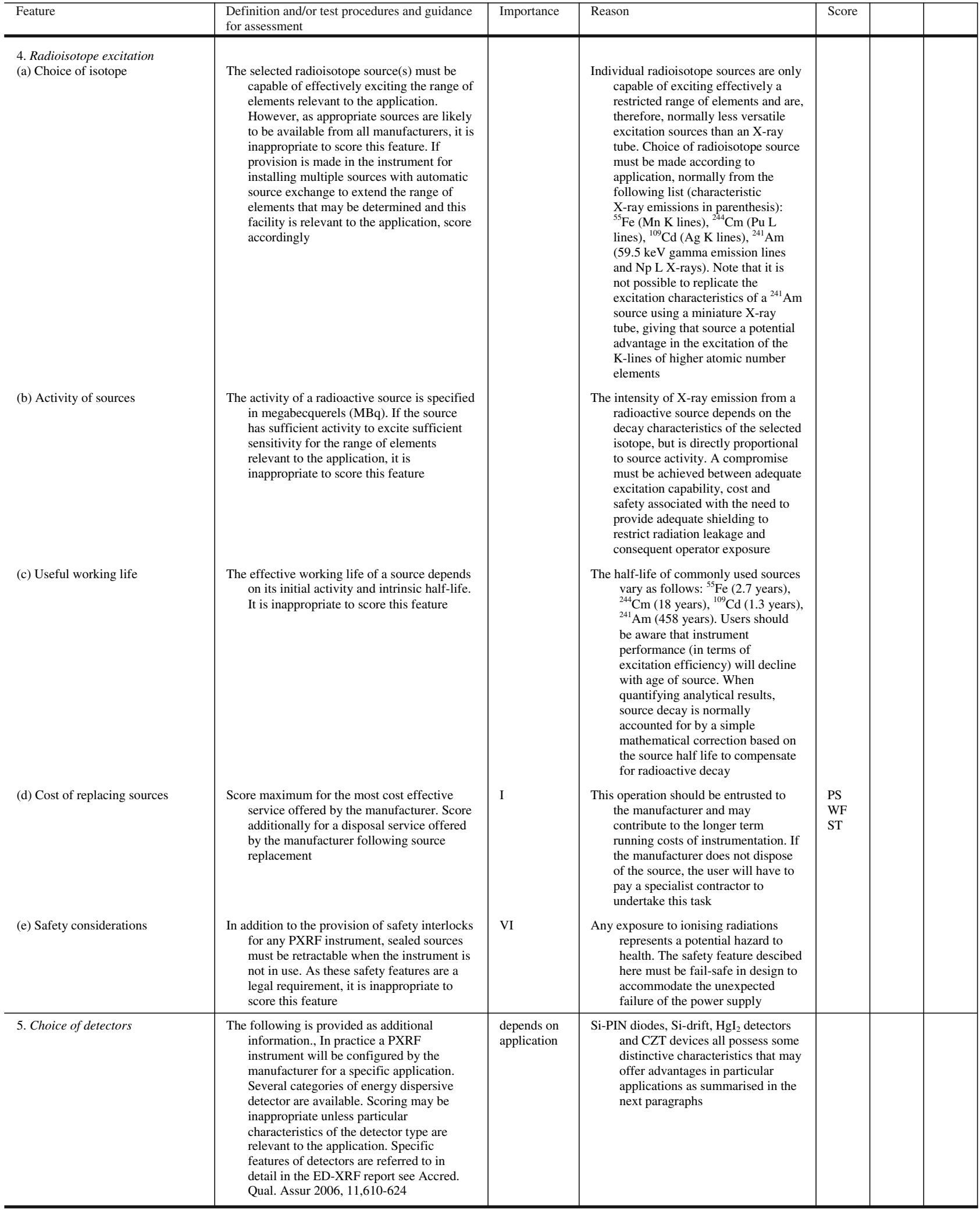


Table 1 continued

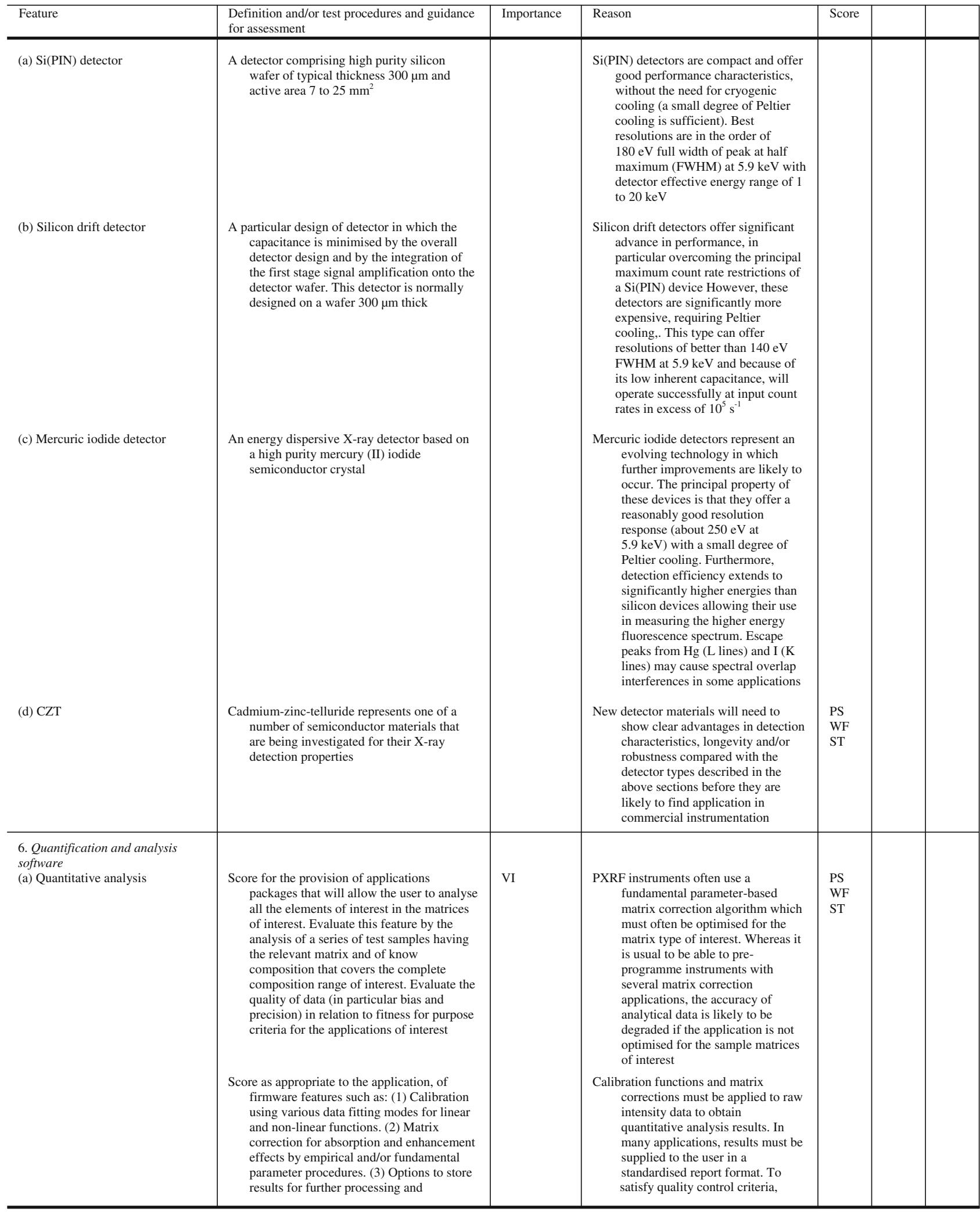


Table 1 continued

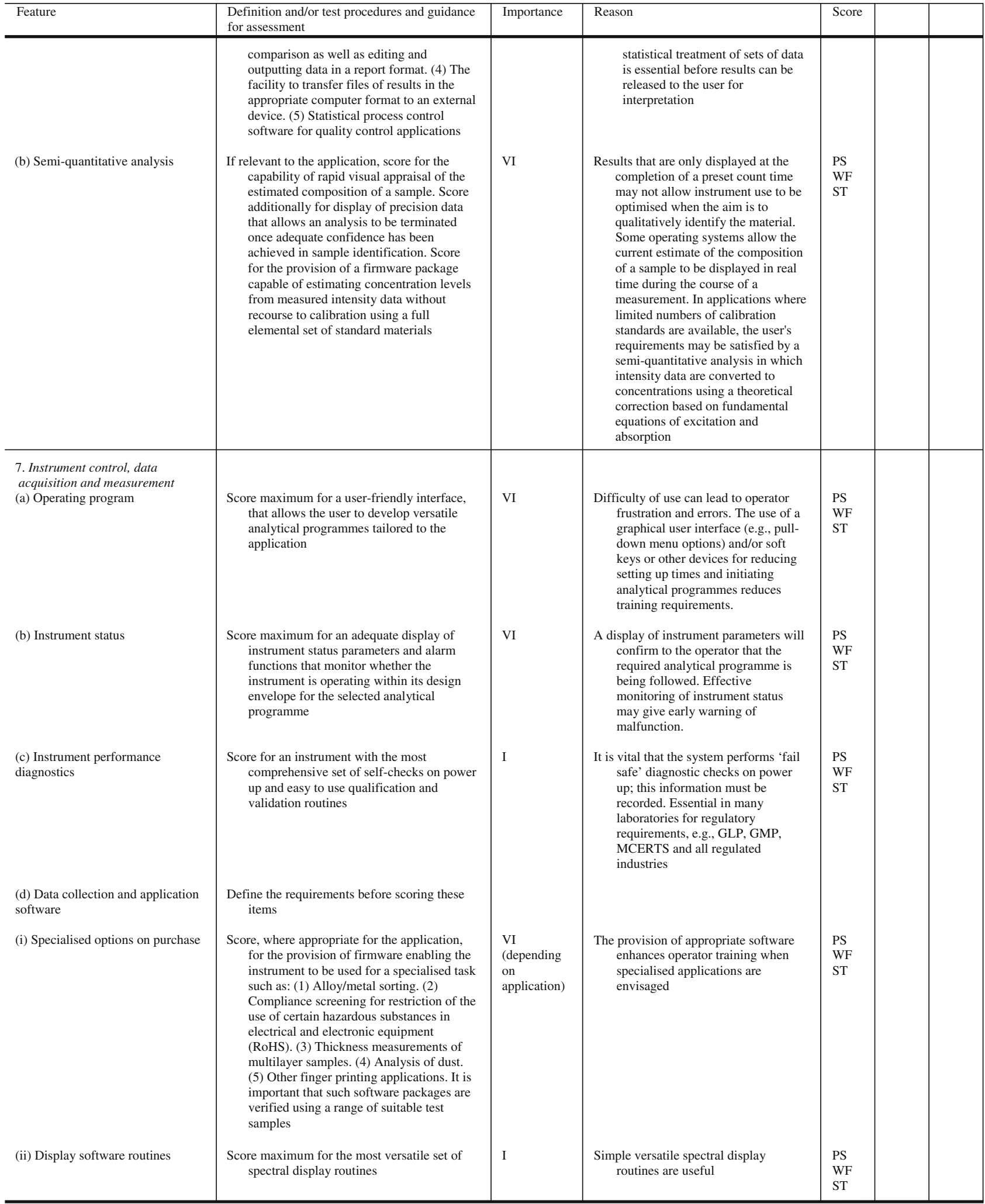


Table 1 continued

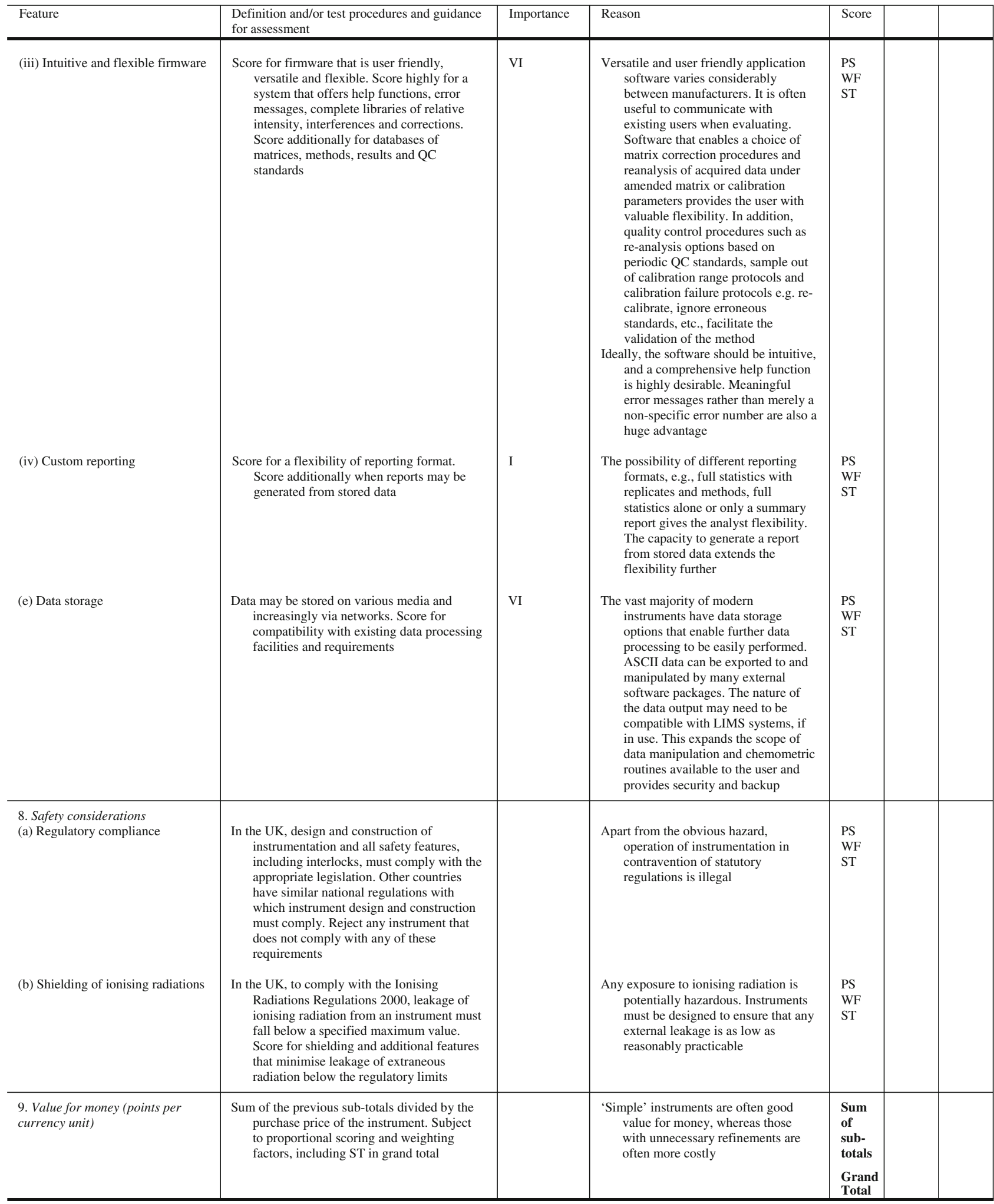




\section{Other reports}

The Analytical Methods Committee has published the following reports in the series:

Part I Atomic absorption spectrophotometers, primarily for use with flames (1984) Anal Proc 21:45. Revised in (1998) Analyst 123:1407

Part II Atomic absorption spectrometers, primarily for use with electrothermal atomizers (1985) Anal Proc 22:128. Revised in (1998) Analyst 123:1415

Part III Polychromators for use in emission spectrometry with ICP sources (1986) Anal Proc 23:109

Part IV Monochromators for use in emission spectrometry with ICP sources (1987) Anal Proc 24:3

Part V Inductively coupled plasma sources for use in emission spectrometry (1987) Anal Proc 24:266

Part VI Wavelength dispersive X-ray spectrometers (1990) Anal Proc 27:324

Part VII Simultaneous wavelength dispersive X-ray spectrometers (1991) Anal Proc 28:312

Part VIII Instrumentation for gas-liquid chromatography (1993) Anal Proc 30:296

Part IX Instrumentation for high-performance liquid chromatography (1997) Analyst 122:387

Part X Instrumentation for inductively coupled plasma mass spectrometry (1997) Analyst 122:393

Part XI Instrumentation for molecular fluorescence spectrometry (1998) Analyst 123:1649
Part XII Instrumentation for capillary electrophoresis (2000) Analyst 125:361

Part XIII Instrumentation for UV-VIS-NIR spectrometry (2000) Analyst 125:367

Part XIV Instrumentation for Fourier transform infrared spectrometry (2000) Analyst $125: 375$

Part XV Instrumentation for gas chromatography-ion trap mass spectrometry (2001) Analyst 126:953

Part XVI Evaluation of general user NMR spectrometers (2006) Accred Qual Assur 11:130-137

Part XVII Instrumentation for inductively coupled emission spectrometers. (2005) Accred Qual Assur 10:155-159

Part XVIII Instrumentation for differential scanning calorimetry (2005) Accred Qual Assur 10:160-163

Part XIX CHNS elemental analysers (2006) Accred Qual Assur 11:569-576

Part XX Instrumentation for energy dispersive X-ray fluorescence spectrometry (2006) Accred Qual Assur 11:610-624

Part XXI NIR Instrumentation for process control (2006) Accred Qual Assur 11:236-237

Part XXII Instrumentation for liquid chromatography/ mass spectrometry (2007) Accred Qual Assur 12:3-11

Part XXIII Instrumentation for portable X-ray fluorescence spectrometry (2008) Accred Qual Assur. doi:10.1007/s00769-008-0358-7 